\title{
Institutionalization and Humanization in Personnel Management in Colleges and Universities
}

\author{
Xiaojun Dai \\ Human Resources Office, Nanjing Forest Police College, Nanjing 210023, China \\ daixj@nfpc.edu.cn
}

Keywords: Personnel management; colleges and universities; institutionalization; humanization.

\begin{abstract}
Personnel management in colleges and universities should attach importance to both system construction and humanistic care. Managers should not only pay attention to the structural function of organizational behavior, but also notice the active role of teachers. They should pay attention not only to the rational aspect of human beings but also to the non-rational aspect of human beings. This research analyzes the personnel management practice in colleges and universities from the perspective of Marxist management philosophy, and constructs a management paradigm that integrates value rationality with instrumental rationality. Finally, it puts forward the direction of personnel management innovation in colleges and universities in our country.
\end{abstract}

\section{Introduction}

Personnel management in colleges and universities is the core content of management in colleges and universities, and is the organization and coordination behaviors of employing, allocating, examining, rewarding and punishing, cultivating and using teaching and administrative staff, under the guidance of educational management theory, taking people engaged in teaching, scientific research and management activities as well as the mutual relations among those people as the object, in order to ensure the normal development and effective operation of teaching and scientific research in colleges and universities [1]. With the increasingly fierce competition of talents and the continuous prominence of management efficiency, how to embody modern management theories, methods and methods in the process of personnel management in colleges and universities, and how to maximize the benefits of personnel management in colleges and universities in the integration and unification of institutionalization and humanization are issues that we should keep thinking about.

\section{Institutionalization: Realistic Basis of Personnel Management in Colleges and Universities}

Institutionalized management is a teaching management concept and mode that uses system norms as the basic means to engage in administrative behaviors, thus realizing educational management goals. It relies on external rules and regulations as well as the rational authority built on this basis. It is closely linked with scientism's educational management view, saying "there is an objective view that enables people to engage in value-neutral research on management; there is a kind of scientific knowledge that enables people to control and improve organizations; there is a rational basis for human decision-making to work together, and there is a technical management view to improve the efficiency of organizations.” It emphasizes the experience and demonstration in education management, focuses on the organizational relationship and structure of the university, and pays attention to human cognitive rationality.

Personnel management in colleges and universities includes organization setup, established posts approval, cadre management, job evaluation and recruitment, immigration management, talent introduction, talent training, attendance check, award evaluation, resignation and transfer, salary and welfare, social insurance, retirement management, personnel file management and other aspects [2]. It needs to face numerous and complicated personnel relationships, deal with various personnel conflicts, and involve various interests of teaching staff. At this time, strict and consistent rules as well as regulations will become the guarantee of 
fair "legal institutions". Therefore, institutionalization should be the foundation and foothold of personnel management in colleges and universities.

Indeed, the aim of institutionalized management is to use a uniform scale to fairly measure the behaviors and relationships of all organizations or people, so that the collective will can be implemented and the university management goals can be efficiently realized. However, in order to ensure the long-term and effective continuation of the university's management cooperation behavior and realize the essence of management, the university faculty's attitude towards personnel system identification is crucial, while the external behavior performance affects the efficiency and ability of management as well as the cohesion of the university.

The external behavior determined by the attitude of identification is obedience. Obedience can be divided into two types: compulsory obedience and identification obedience. Those who are forced to obey have resistance or opposition to personnel regulations and management methods, while the latter agree with these regulations and management methods in cognition and emotion. If the obedience of university faculty to the university personnel system belongs to identification obedience, it is conducive to the construction and reform of the personnel system, to the improvement of management efficiency, and to the stability and development of the university. If this kind of obedience is compulsory obedience, even if the institutionalized management reaches the management goal in a short period of time, in the long run, it will limit the potential of university teachers and affect the achievement of the university management goal. Therefore, in order to obtain the approval of the vast majority of teaching staff, the personnel management system must be revised or reformed in a timely manner according to changes in the actual situation of the university. One mistake in understanding is the omnipotent theory of system. It would be wrong to think that once a strict system has been established, it will be once and for all. There are problems of implementation for the system. If we believe that a strict system is implemented impartially, we will achieve the management goal. That is not enough; the humanistic factors that the system itself should contain are even more important in some cases.

\section{Humanization: Value Orientation of Personnel Management in Colleges and Universities}

Humanization management refers to the management concept and mode that is people-oriented in the process of management, pays full attention to human dignity, value and human nature requirements, cares about human development, mobilizes people's enthusiasm, initiative and creativity, and develops people's potential so as to achieve the best results $[3,4]$. It reflects the respect for people's thinking mode and value orientation.

From the perspective of humanization, the starting point of management is human, and the ultimate goal is also human. For colleges and universities, human resources-teachers are the foundation, the resources with soul and innovative, and the resources that control and utilize all other resources such as material resources, financial resources and information. The implementation of humanization management for university teachers is inevitable for the combination of management theory and teachers' actual development, the need of university teachers' working characteristics, and the requirement of the times for the development of colleges and universities.

First of all, people have a variety of needs. As teachers in colleges and universities, they attach particular importance to the realization of self-worth. In 1943 Maslow put forward five hierarchies of needs in his article A Theory of Human Motivation, namely, physiological needs, safety needs, social needs, esteem needs and self-fulfillment needs. Alderfer divides human needs into three categories: the need for survival, the need for mutual relations and the need for growth and development. McLelland divides human needs into the needs of power, friendship and achievement. Thus, it can be seen that the realization of human self-worth is the highest pursuit of human beings and an important content that cannot be ignored in the process of personnel management. Second, the object of personnel management in colleges and universities often has higher academic prestige than managers. College and university teachers are highly-educated and they have profound professional knowledge as well as good cultural quality. So they have the need to be respected and understood by others psychologically. At the same time, they have strong democratic concepts, and dare to 
challenge authority. Humanistic care is especially important. Therefore, it is absolutely not desirable to adopt a single administrative command-based management method. The humanistic management concept and mode are more suitable to the specific reality of colleges and universities. Third, personnel management is not a purely single management behavior, but closely intertwined with the two major tasks of colleges and universities--teaching and scientific research activities. In management, the urgent need and necessity of teaching and scientific research activities must be considered. This requires the establishment of a people-oriented management mechanism that gives full attention to talents, reflects the guiding, shaping and encouraging functions, so as to attract and stabilize talents and win a place in the international environment of talent competition.

One of the misconceptions here is that humanization management is loose and simple, or the necessity of the system is denied. In the process of management, people's cognitive factors and irrational factors will affect the effectiveness of system management. If only "humanization" is emphasized, the role of people's subjective irrational values will definitely be excessively emphasized, thus ignoring the necessity of static research. The system may become dispensable and the phenomenon of "rule of man" may also occur. Because management involves various personnel issues, fairness and justice are also difficult to practice, so that the original intention of humanization management may be violated.

\section{Management Paradigm: Construction of Humanistic Values within the Framework of the System}

In the process of deducting management theory, institutionalization and humanization seem to be two poles of theoretical research and management practice. The traditional administrative management theory at the end of the 19th century, based on the micro-management theories of Taylor and Fa Yueer, chose the technical route, carried out systematic research, and emphasized "administrative institutionalization" as well as the management style and value orientation of "efficiency first". to some extent, it overcame the problems of bureaucracy and low administrative efficiency at that time. However, after 1960, due to the neglect of civil rights and fairness, the society had a crisis of trust in the government [5]. The new public administration theory came into being, paying attention to human nature, emphasizing "humanism", "administrative democratization" as well as social fairness and democratic values. Nevertheless, owing to the decline of the government's administrative ability and management efficiency, the new public administration theory was in crisis again. After the Western economics experienced the innovation of the public choice theory represented by Buchanan and the new institutional economics represented by North, the new public administration theory came into being after 1980. Osborne and Gueble put forward the concepts of "government enterprising tendency" and "public customization", and implied the concept of management service, trying to return public management to the market management mode, and also trying to find a balance in institutionalized management and humanization management.

For personnel management in colleges and universities, something can learn from it. In fact, institutionalization and humanization are not contrary.

First, good institutionalized management contains humanistic characteristics. This is reflected in two aspects; one is the potential of the system. "A good system can prevent bad people from running amuck; a bad system would prevent good people from doing good things fully and even lead to the opposite side. If the system is humanized and pays close attention to the value and immediate interests of teachers, it can stimulate the potential and enthusiasm of the teaching staff, promote fair competition and eliminate the fittest, and ensure the unity of efficiency and fairness. Another one the implementation of the system. Whether the personnel rules and regulations in colleges and universities can be strictly, fairly and effectively implemented will affect the established management objectives. If managers are lack of system awareness, sense of responsibility, and transpositional consideration in handling specific affairs, then perhaps the system will become a dead letter; perhaps the system will be rigid, and the legal campus environment and management atmosphere will not be formed. That everyone is equal in front of the system is the basic idea, and compliance with the system should be universal behavior [6]. The good or bad execution of the system determines the faculty's psychological identification with the personnel department and the university. Therefore, although 
institutionalized management focuses on the regularity, scientificalness and rationality in the process of management, it does not negate human nature. Instead, extremely rigid management methods will reduce the adaptability of management itself.

Second, beneficial humanization tendency depends on the system foundation. The effectiveness of management depends on the rationality of system control. Without system restriction, the phenomenon of rule of man will appear. A fair, just and open modern management method must be flexible enough to meet the needs of human nature. Certainly, the foundation of this system should be standardized and scientific, with a complete evaluation system and clear rewards and punishments. For example, in order to find an optimal balance between stabilizing talents and introducing talents, so that all high-level talents can make best use of their talents, talking in generalities is useless. It is necessary to formulate relevant documents and take the system as the guarantee, so as to take various measures and increase capital investment in accordance with the "law". On the one hand, it is necessary to vigorously introduce high-level talents. On the other hand, it is important to support disciplines, leaders in their chosen fields of learning and backbone teachers in universities. Otherwise, when contradictions and conflicts arise, they could not found rational authority, which will lead to a crisis of legitimacy.

Third, institutionalization is inseparable from humanization. Management has three major functions that are encouragement, service and control, which includes attention to people's inner world and constraint of external behavior, and merges the two into the behavior paradigm of managers. The system is static while management is dynamic, so the dynamic management cannot be separated from people and the organizational structure of colleges and universities as well as the individual factors in the management network. This shows that facts and values are inseparable. Values and facts (including emotional factors of teaching and administrative staff) are what personnel managers should pay attention to after implementing rules and regulations, and are also the basis for verifying the system's potential and system's execution. Therefore, tangible constraints and intangible care can be organically unified, and the system's benefits and cohesive force can be directly proportional.

Therefore, managers should pay attention to the following three aspects in the process of personnel management in colleges and universities:

Firstly, Managers should consolidate the management foundation and attach importance to the construction of personnel system. Personnel work must have a complete system, in order to enhance management connotation and expand management value on this basis. For one thing, managers should unify their understanding, put the work of personnel and talents into an important strategic position in the development of the university, and realize the core role of the construction of teachers' team as well as the importance of building management team. For another, they should clarify the thinking of personnel work and create a good atmosphere for the stability and development of high-level personnel. Besides, they should improve personnel rules and regulations so that there are laws to abide by for personnel management and managers can ensure that the laws are strictly observed.

Secondly, the system should be taken as a framework to highlight the cultural connotation of personnel managers. In management theory, whether it is "economic man” in theory X, "social man” in theory $\mathrm{Y}$, or "complex man" in theory Z, the focus is always "man". The focus of personnel management in colleges and universities is also "people". in order to do well in management, it must be people-oriented, with people at the core, and the humanization management should be contained in it. First, the personnel management in colleges and universities should conform to their own characteristics. The management thoughts, concepts, methods and ways should conform to the specific characteristics of personnel work in colleges and universities and the actual situation. Besides, personnel management should be changed from control to service. Managers should not only improve their own quality and pay attention to honesty, courtesy as well as trust, but also continuously improve management methods, so as to communicate, support and interact with each other, respect, understand and care about the teaching staff in the management process. Moreover, the achievement of management objectives not only focuses on the satisfaction of the university organization and the successful completion of specific affairs, but also includes psychological identification, motivation, potential exertion and human nature satisfaction of the teaching staff. Especially when the personnel system 
reform (organizational system reform, personnel system reform, distribution system reform, logistics socialization reform, etc.) is being carried out, humanization should be involved in the system objectives of competitive incentives, and various contradictions should be resolved humanely in the institutional framework.

Thirdly, to innovate the personnel management paradigm. All the teaching staff should be treated equally. Managers are supposed to handle all kinds of relations and solve various problems fairly. The content of management is comprehensive, specific and complicated, involving all aspects of "reputation" and "benefit" of teaching staff. The implementation method of management is authoritative. Its scientific and instrumental tendency based on the system is obvious. If the system norms are broken, the manager or the management itself will be caught in the shackles of embarrassment and self-contradiction. However, the management organization is made up of people, so management and decision-making must involve all aspects of people's irrational factors. The scientific management view is always integrated with the subjective value of human beings, which embodies the subjective value of researchers and managers in the management process. At the same time, the complexity of human determines the cultivation direction of value orientation. Therefore, in the process of personnel management in colleges and universities, attention has been paid to the mechanical and inflexible system measurement, ignoring the humanistic concept, which leads to the emotional opposition of the subordinates. Paying attention to the humanistic care for each specific object, but ignoring the system requirements will lead to management confusion and inefficiency.

\section{Summary}

Fairness and democracy should coexist; efficiency and benefits should coexist. Institutionalized management does not mean the authoritarian tendency of personnel management. Its ultimate meaning should contain some soft value orientation. Cultural management of human beings does not mean the subjective tendency of personnel management. It is bound to have a solid rigid foundation. The relationship between institutionalization and humanization is not a trade-off relationship, but a mutual-generation relationship in the new platform and space. In the process of personnel management in colleges and universities, attention should be paid to both system construction and humanistic care. Managers should not only pay attention to the structural function of organizational behavior, but also be aware of the active role of teachers. They should care about not only the rational aspect of human beings but also to the irrational aspect of human beings.

\section{References}

[1]. Ming, Yuemei, "Research on New University Education Management Methods based on the Combination of Humanized and Institutionalized,” International Technology Management, vol. 108, pp. 99-101, September 2015. (In Chinese)

[2]. ZHANG Fan, WEI Xueli, CAI Feng, "Study on Humanization of University Management from the Knowledge Management Perspective,” Modern Education Management, vol. 17, pp. 15-19, August 2016. (In Chinese)

[3]. PANG Hongmei, QIU Ailian, "People-oriented Management: the New Knowledge in the Development of University Informatization,” Modern Education Management, vol. 18, pp. 56-61, November 2017. (In Chinese)

[4]. DAI Jian-bo, "The Influence Factors and Management Countermeasures of Faculty Mobility of Local Universities under the Perspective of Humanity Assumption Theory,” University Education Science, vol. 13, pp. 58-63, July 2016. (In Chinese)

[5]. Lü Baoping, "The Influence Factors and Management Countermeasures of Faculty Mobility of Local Universities under the Perspective of Humanity Assumption Theory,” Journal of national academy of education administration, vol. 112, pp. 66-69, May 2016. (In Chinese) 
[6]. Zhang Lina, Xia Qingli, “The Realistic Dilemma and Countermeasure of Human Resource Management in Colleges and Universities--A Discussion on the Informatization Construction of Personnel Archives in Colleges and Universities Based on the Big Data Thinking," Academic Forum, vol. 39, pp. 157-161, April 2016. (In Chinese) 